\title{
The Role of SMEs in Strengthening the UK-USA Partnership
}

https://doi.org/10.21272/sec.5(1).66-78.2021.

Dr. Raymond Davies, ORCID: https://orcid.org/0000-0002-8487-0120

$\mathrm{PhD}$, Advisor, Infinite Sum Modelling LLC, Seattle USA and Member, Board of Directors, British American Business Connections of Pacific Northwest, Seattle USA

Dr. Badri Narayanan Gopalakrishnan, ORCID: https://orcid.org/0000-0001-9628-8173

$\mathrm{PhD}$, Senior Economist, University of Washington Seattle, Founder-Director, Infinite Sum Modelling LLC, Seattle USA and Member, Board of Directors, British American Business Connections of Pacific Northwest, Seattle, USA

Mr. Adhithya Balasubramanian, ORCID: https://orcid.org/0000-0001-9215-9569

Student Researcher, Shiv Nadar University, India and Intern, Infinite Sum Modelling LLC, Seattle USA

\begin{abstract}
UK-U.S. Partnership has a historical legacy in the political, cultural, and economic matters concerning both countries mutually. Trade has played a significant role in boosting economic relationships between both countries. This study aims to study SMEs' role (Small and Medium Enterprises) in the post-COVID trade policy with an emphasis on technological transformation and economic recovery. Data shows that SMEs have risen to prominence in the last decade in both countries; SMEs consists of more than $95 \%$ of businesses and are employing close to $50 \%$ or more in both countries. SME traders from the U.K. mutually identify the U.S. as a significant destination for imports and exports in the next three years. COVID-19 has disrupted businesses worldwide, forcing businesses to rethink their business strategies, especially the SMEs. We aim to look at how global pandemic, trade, business policy blend together under the context of changing technology and supply chains around the world. We suggest the need for rigorous and integrated approach to trade policy going forward which will play a major role in the business ecosystems for the two countries. This study points to the research noting the importance of SME entrepreneurial employers' presence in the last economic recovery. The key is to achieve a cluster of SME supply chains collaborating and inter-linked with inherent entrepreneurial leadership and innovation within specific markets. In the present scenario, it is not the size but the quality of business relationships that can accelerate core competencies and tie companies to each other across the supply chain. SMEs' flexibility is a vital tool to gain efficiencies, and bilateral free trade agreements can prove to be a useful tool to gain greater flexibility due to better trust and trade connectedness, as observed in the literature.
\end{abstract}

Keywords: SME, USA, UK, supply-chain, entrepreneurship, trade.

JEL Classification: F13, F53, F68, L53.

Cite as: Davies, R., Gopalakrishnan, B.N., Balasubramanian, A. (2021). The Role of SMEs in Strengthening the UK-USA Partnership. SocioEconomic Challenges, 5(1), 66-78. https://doi.org/10.21272/sec.5(1).66-78.2021.

Received: 05.02.2021

Accepted: 13.03.2021

Published: 30.03 .2021

Copyright: (C) 2021 by the authors. Licensee Sumy State University, Ukraine. This article is an open access article distributed under the terms and conditions of the Creative Commons Attribution (CC BY) license (https:// creativecommons.org/licenses/by/4.0/).

\section{Introduction}

The United Kingdom's withdrawal from the European Union (EU) coincided with the coronavirus disease pandemic while their other significant trading partner the United States of America shifts its trade policy. The United Kingdom has therefore undertaken a comprehensive bi-lateral approach to its trade arrangements. This 
study aims to discuss key points under the trade partnership between the United Kingdom (UK) and the United States of America (U.S.), emphasising small and medium enterprises (SMEs). The primary motive of the study is to invoke discussion on the following:

1. Movement from multilateral free trade policies to mutual interest, trust, and reciprocity based bilateral agreements between pairs of countries.

2. SMEs, have been the primary front runners contributing to the above-described change in pattern in trade policy.

Further, this study observes pertinent points regarding SMEs and the impact of the coronavirus disease (COVID) pandemic in the following manner:

1. How will technological transformation post-COVID affect SMEs? There could be advantages and disadvantages ahead.

2. Can we view SMEs as key drivers in the bottom-up recovery of an economy post-COVID? Analysing its significance in the U.S.-UK trade policies is important.

This paper is divided into six sections: section 1- the introduction, section 2 - a review of the literature motivating the discussion; section 3 - data analysis on SMEs in the UK and USA; section 4 - insights on technological disruptions and their relevance for SMEs and trade policy in a post-COVID world; section 5 - the need for a series of rigorous studies to inform trade policy; section 6 - conclusion identifying a broad vision for the way forward.

\section{Motivation and Literature Review}

Past literature shows that bilateral trade agreements have gained economic relevance in the global trade scenario [3]. In the same paper, they analyse trade interconnectedness (TI), which measures the relative importance of production linkages between two countries in the international trade network. A positive TI indicates easier access to a partners' domestic markets, resulting in an average increase in trade volumes. The results show that bilateral trade agreements have resulted in substantial positive TI values in most G20 countries except China.

Following the above point, we also observe that transportation costs, differences in country sizes, and comparative advantages are obstacles to the proliferation of multilateral free trade agreements.

In contrast, bilateral free trade agreements are looked at as Pareto-optimal outcomes worldwide for various parameters [4]. With this gradual trend in the change of global trade patterns, we turn our focus to Small and Medium Enterprises (SMEs) in this process.

The importance of SMEs' cannot be neglected in the last decade with a further rising emphasis on contribution to global trade.

For example, in 2012, it was estimated that $88 \%$ of firms exporting to the U.S. from the EU were SMEs, with a higher percentage (93\%) from the UK [8]. In early 2018, a special SME dialogue was launched between the UK and U.S., along with a special focus on an IP toolkit for SMEs [7]. Further, a 2020 report from the UK Trade Policy Observatory (UKTPO) and Federation of Small Businesses (FSB) remarks that $99.9 \%$ of businesses in the UK are SMEs with the U.S. identified as the most 'important' exporter destination (46\%) and the most important import origin market (31\%) for SMEs in the UK for the next three years [6].

However, the COVID pandemic has disrupted SME business around the world, including the UK and U.S., and provide a shock impact on economic activities. Early signs of technological transformation may affect SMEs in a manner where digital resistance and resilience will take a new shape. For example, a recent study says that many countries have accepted e-prescriptions for medical purposes from traditional prescription in a matter of a few days showing that digital resistances and aversion might reduce drastically [5]. The world has a fast-tracked automation movement with increased emphasis on teleoperations and remote control with IoT and IT platforms as natural candidates for such transformation [5]. "SMEs cobots (collaborative robots) could play a role due to their simple programming and the reduced spaces" [5 p. 9]. 
On the other hand, the uncertain impact being experienced can lead to new asset improvements, which may result in technology disabling or replacing specific jobs. This social cost is worsened by a fall in consumption demand [5].

Technological transformation post-COVID will change the notion of resilience and adaptability to a smarter organisational transformation, including in the case of SMEs. Also, cyber security may pose a threat due to current unpreparedness and awareness to deal with a drastic change in the landscape [5], particularly as SMEs can be seen as weak points in cyber security within supply chains.

While technology is an important issue, the recovery process is the highest priority for governments worldwide. An analysis of the recovery of economies post breakdowns implies strongly that a local level policy effort and judicial promotion of high productivity enterprise development projects are critical for sustainable and equitable development trajectory from the bottom-up [1].

The case of Ireland shows the importance of focus towards local level policy efforts, in this context, the focus towards SME as critical players in the recovery process. After the downfall due to the crash in 2008 until 2012, investment activity has seen a faster rate of increase in SMEs [2]. This has shown a secure link concerning regional unemployment for domestically oriented firms. "The likelihood and level of investment increases with firm size, and is also higher for exporting and innovative SMEs" [2 p.86]. Overall these results showed macroeconomic improvements to the observed investment activity of SMEs [2].

With the increasing relevance of SMEs in global trade and technological shifts for the future, the policy focus on diverting resources towards SMEs to simulate investment, particularly on those that export, is imperative for financial bottom-up recovery stimuli and measures. The UK therefore made a radical shake up to its UK export finance (UKEF) launching a General Export Facility for SMEs in partnership with the UK's leading commercial banks [22].

\section{Analysis of SMEs in USA and UK: A Consolidated View of the SME Sector}

Over the years, we have seen massive growth in small and medium businesses in both countries, in terms of numbers and employment. Though larger enterprises control the trade overall, there has been an increasing trend within SMEs, especially between the U.S. and UK.

\section{Part I: United Kingdom (UK)}

In the UK, businesses employing below 249 employees are considered as SMEs. Figure 1 shows that the maximum growth over the last two decades has been recorded in the SME category. Presently, more than $99 \%$ of businesses in the UK are SMEs.

\section{\% Growth in number of business types from 2000 to 2019}

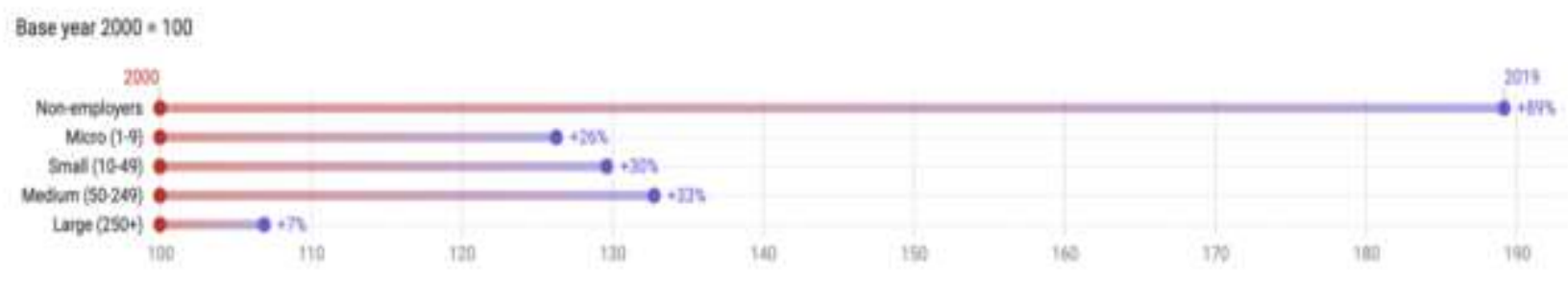

Figure 1. \% Growth in number of business types from 2000 to 2019

Source: Merchant Savvy Report 2020.

We observe a significant number of increases in total employment over the last two decades in the private sector (Figure 2). Most of the employment is in the SME sector, showing the relevance of SMEs in the UK's business environment. Non-employee businesses have maximum employment at present. 


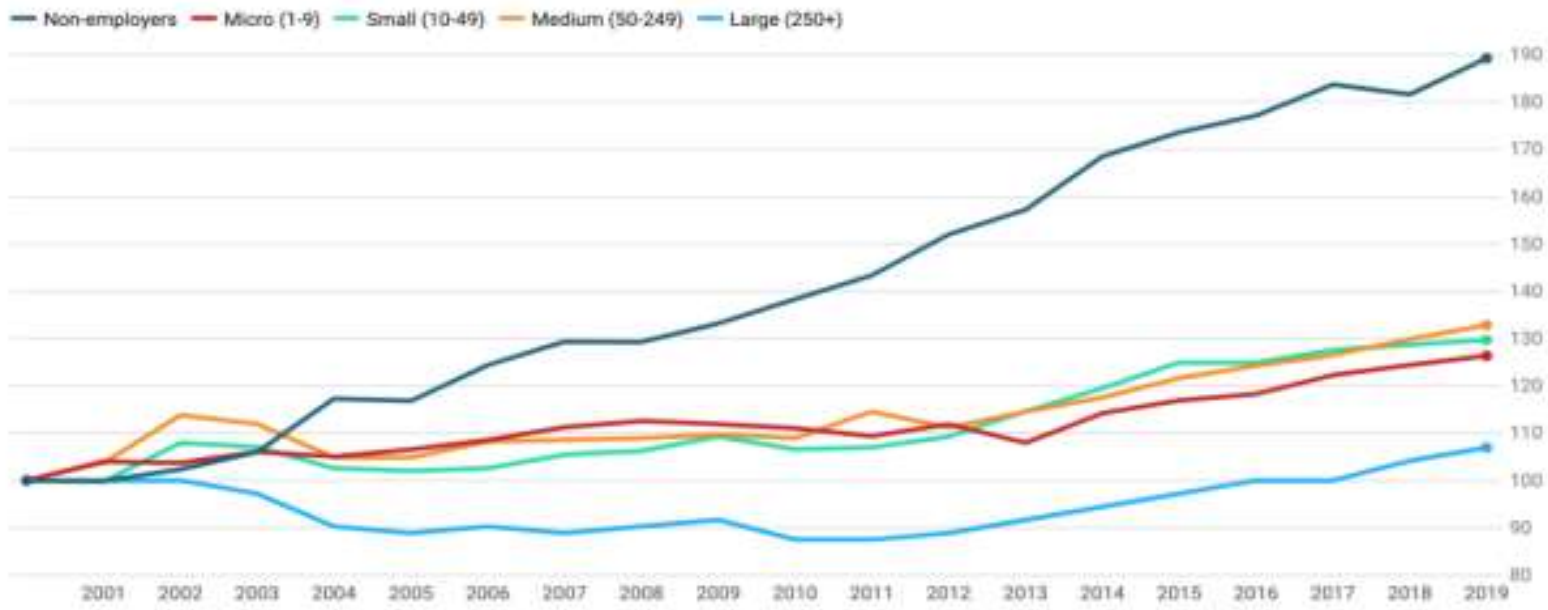

Figure 2. Growth in UK businesses in the private sector by number of employees (2000-2019)

Source: Merchant Savvy Report 2020.

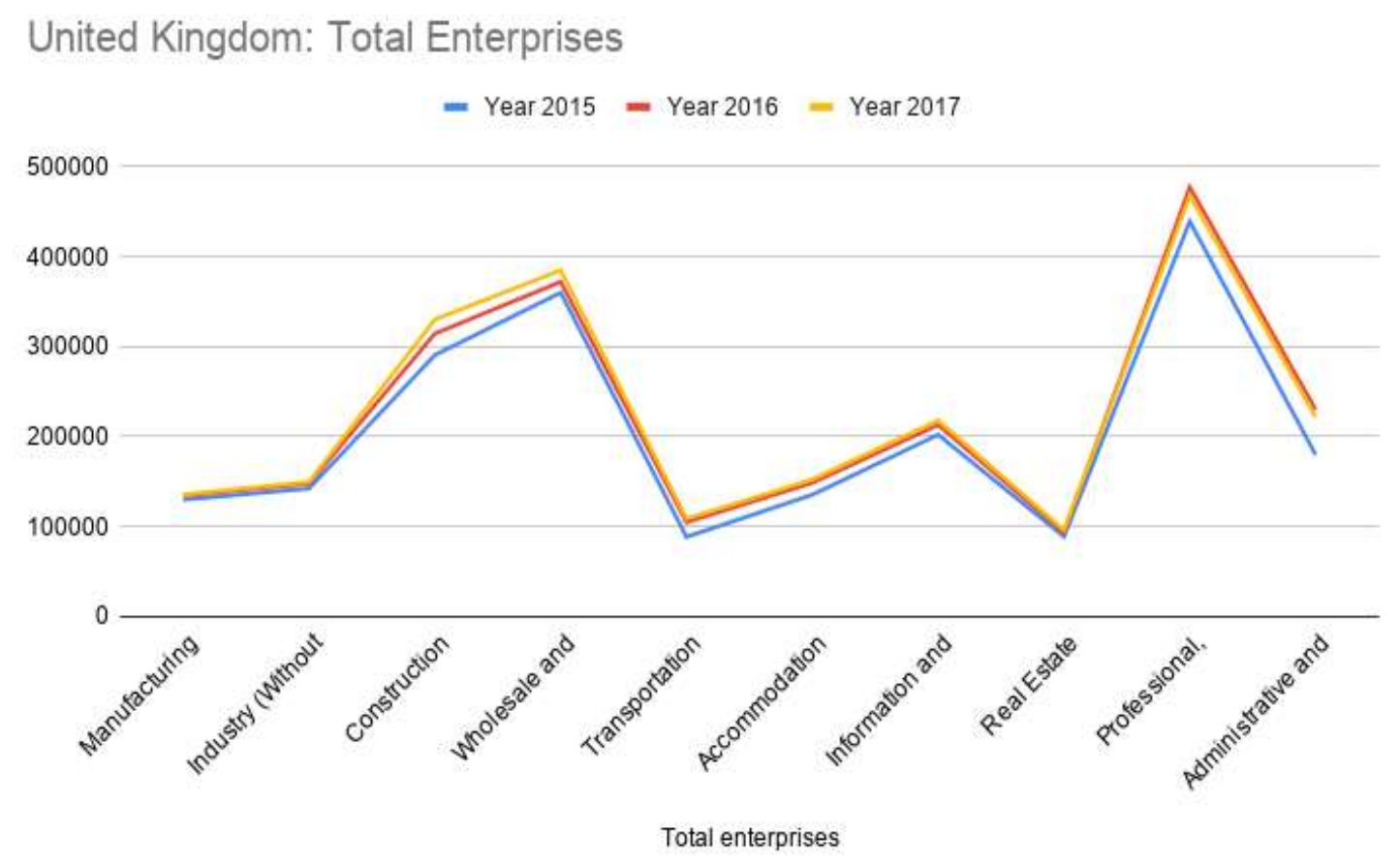

Figure 3. United Kingdom: Total Enterprises

Source: OECD SDBS Structural Business Statistics (ISIC Rev. 4). 


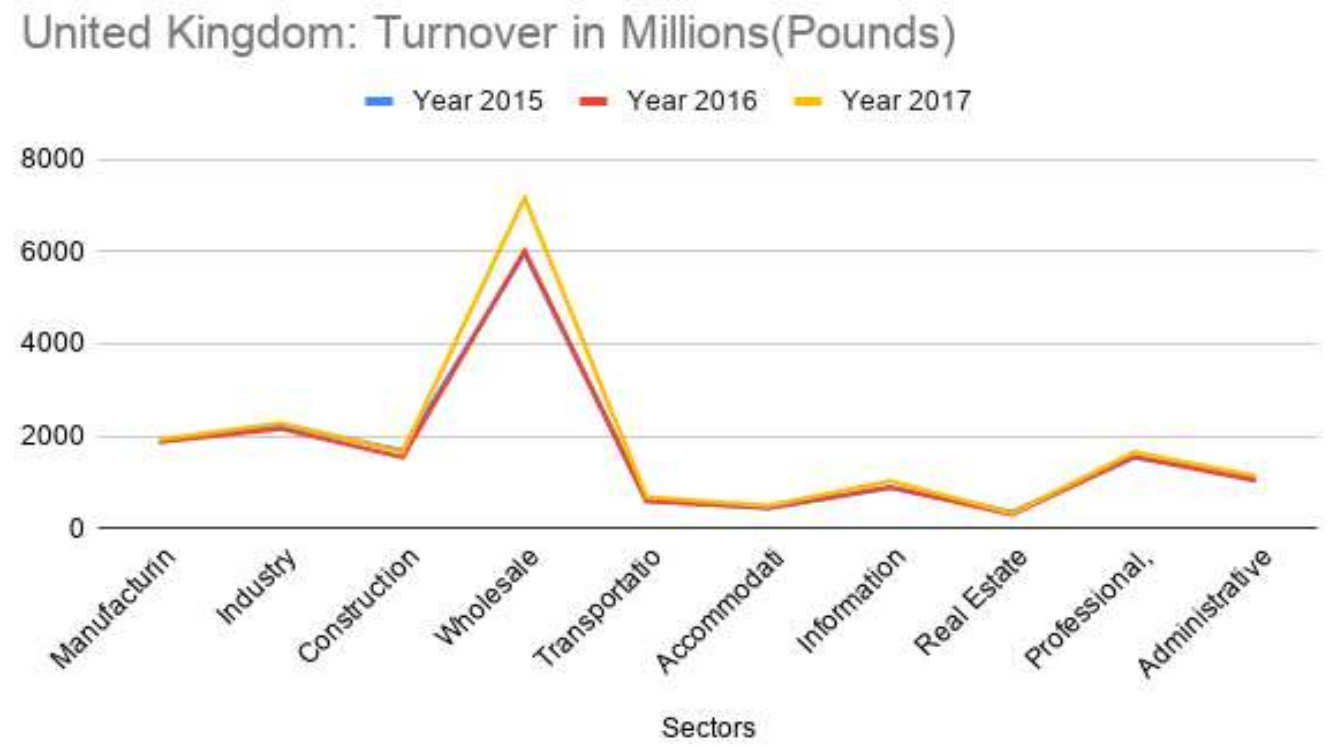

Figure 4. United Kingdom: Turnover in Millions (Pounds)

Source: OECD SDBS Structural Business Statistics (ISIC Rev. 4).

The number of enterprises and turnover, sector wise, for SMEs in the period between 2015 and 2017 are two essential factors (Figures 3 and 4). The professional, scientific, and technical activities sector has the highest number of enterprises, but concerning turnover, it is not the most attractive investment. The turnover has seen the sharpest rise in wholesale and retail trade sector over the three years.

\section{\% of Total UK Employment \& Turnover By Industry Sector (2019)}

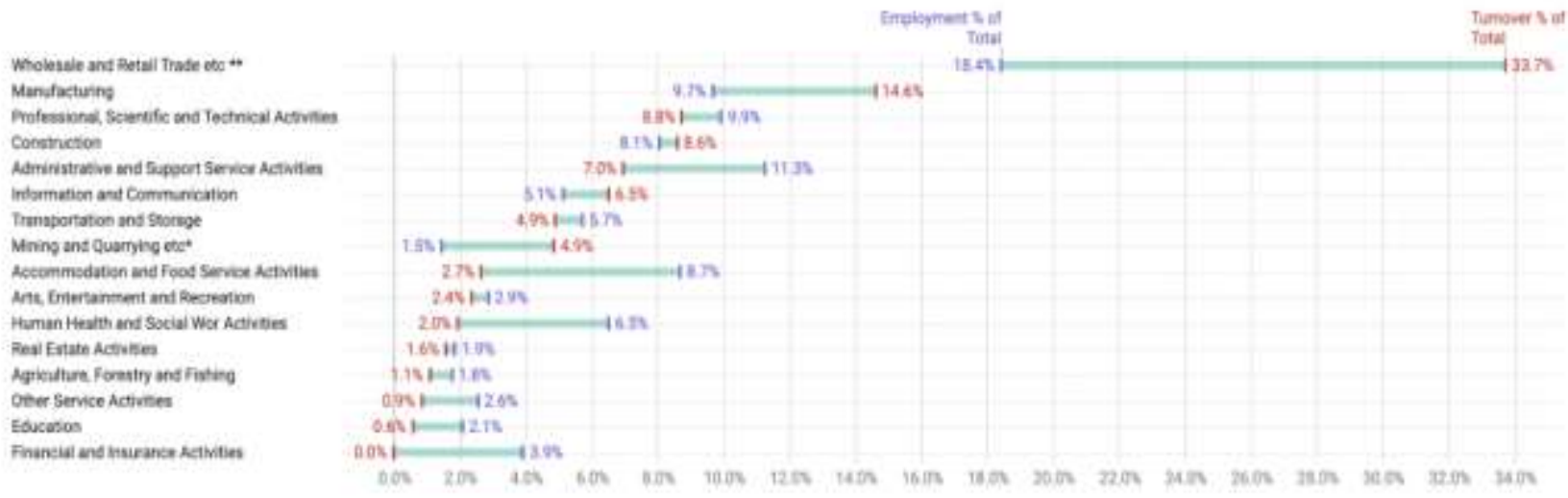

Figure 5. \% of Total UK Employment \& Turnover by Industry Sector (2019)

Source: Merchant Savvy Report 2020.

As an effect of what we saw in the previous two graphs, Figure 5 shows that the maximum number of employees in SMEs is in the wholesale and retail trade, followed by manufacturing in 2019. With regards to turnover, wholesale, and retail trade industry, SMEs have more than doubled the turnover of manufacturing SMEs, showing the sector's attractiveness over the years. 


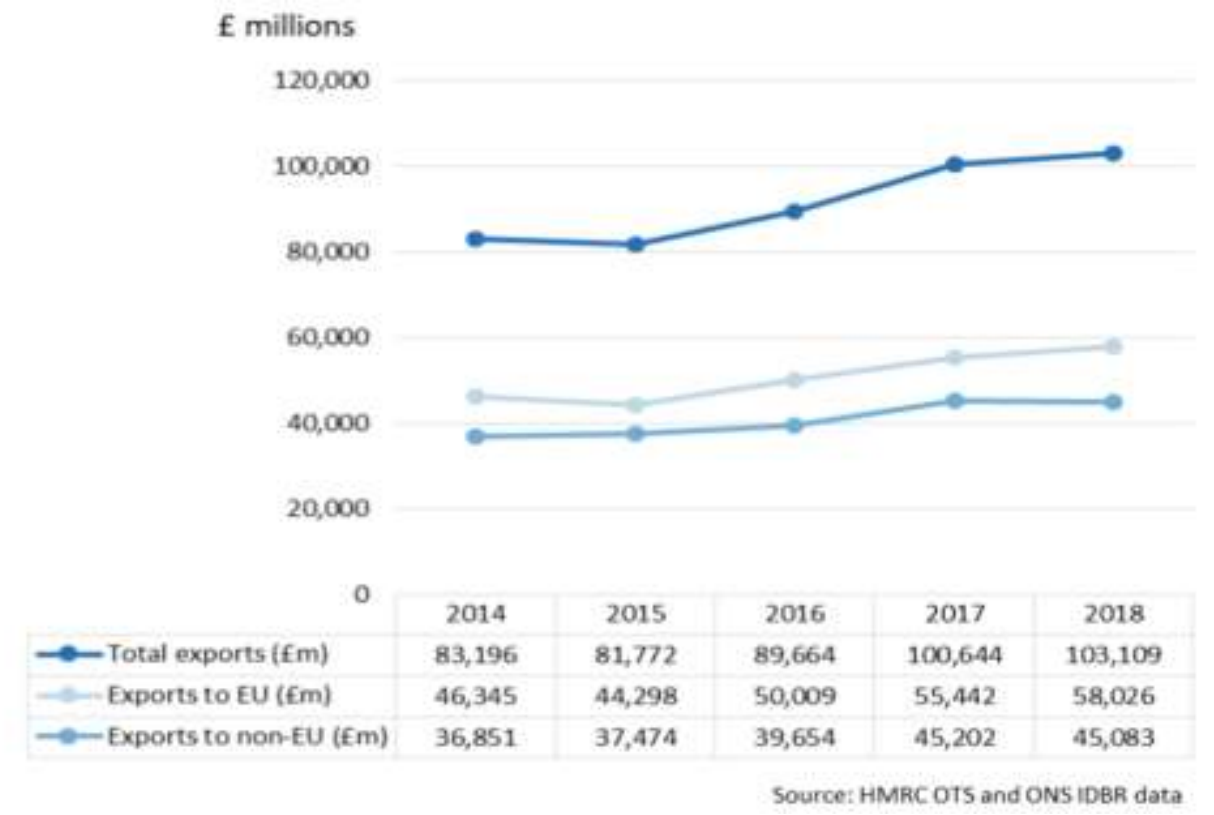

Figure 6. United Kingdom: SME Exports

Source: Overseas Trade Statistics (OTS) and Office for National Statistics (ONS) from Inter-Departmental Business Register (IDBR).

Over the five years (2014-2018), exports have drastically increased with EU exports dominating the market (Figure 6). More firms are growing in their competencies to face the international market with a close to $25 \%$ increase over the period. Simultaneously, Figure 7 shows us the percentage comparison with regards to larger businesses from 2017 to 2018 . More towering businesses dominate trade with higher increases in exports. SMEs import much more, but the larger SMEs (50-249) are also significantly increasing their export share.

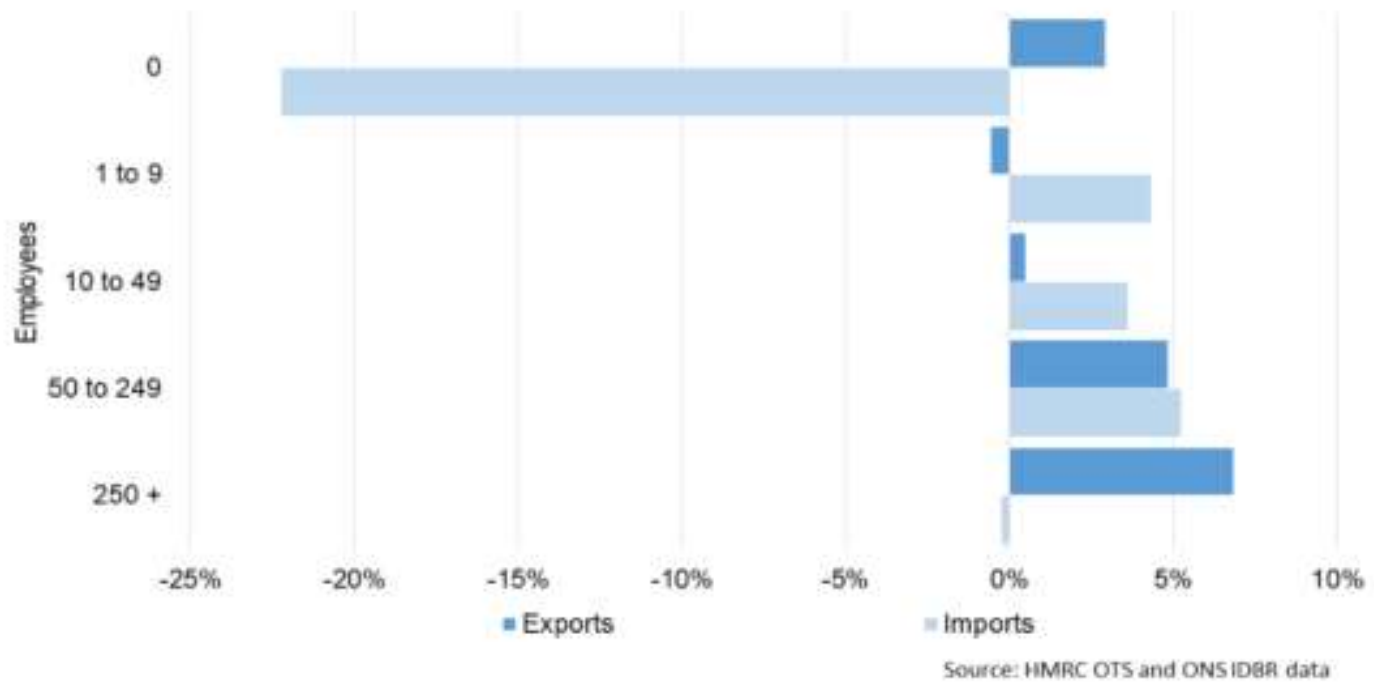

Figure 7. Trade comparison by business size

Source: Overseas Trade Statistics (OTS) and Office for National Statistics (ONS) from Inter-Departmental Business Register (IDBR).

Part II: United States (U.S.)

In the U.S., SMEs are defined as businesses with less than 499 employees. In in 2014 and 2015, wholesale and retail trade have the maximum number of enterprises compared to other sectors (Figure 8). 


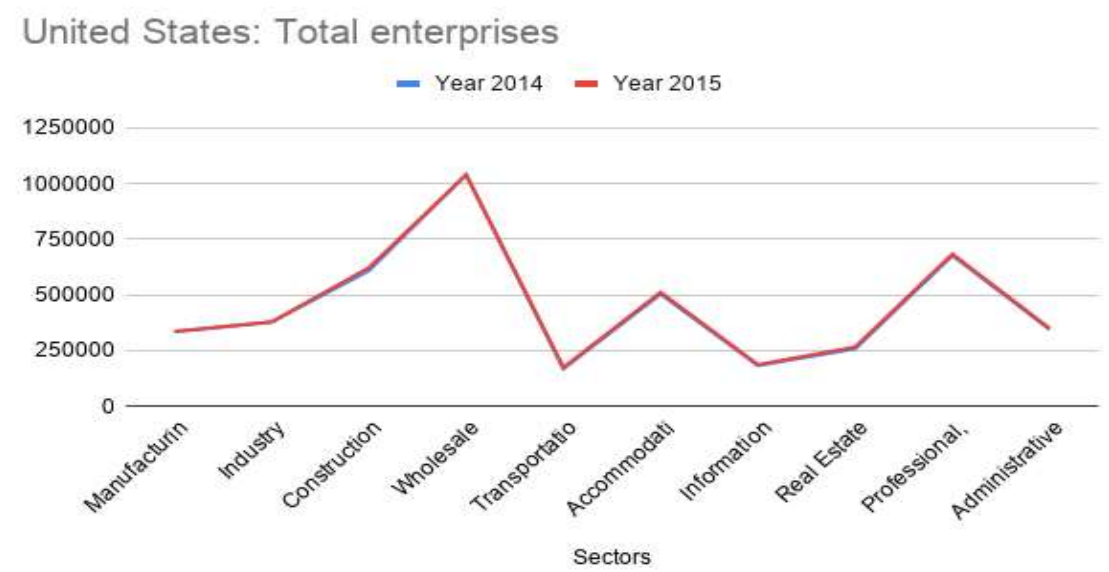

Figure 8. United States: Total enterprises

Source: OECD SDBS Structural Business Statistics (ISIC Rev. 4).

Table 1. \% Employment comparison by business size

\begin{tabular}{|c|c|c|c|}
\hline Year/ Business Size & $1-249$ & $250-499$ & 500 or more \\
\hline 2016 & 46.05 & 7.15 & 46.77 \\
\hline 2017 & 45.82 & 7.2 & 46.95 \\
\hline 2018 & 45.43 & 7.2 & 47.33 \\
\hline 2019 & 45.2 & 7.2 & 47.57 \\
\hline
\end{tabular}

Source: U.S. Bureau of Labor Statistics.

Table 1 highlights the split in employment percentages based on business size. From the graph, we see that in the last four years, around $50 \%$ of the private employment came from the SME market, a statistic remarkably like the UK. However, with direct reference to the UK comparison, employment below the 249 range is lesser in the U.S. The employment of non-employee businesses is excluded. Figures 9 and 10 offer a similar picture of U.S. trade concerning SMEs and large businesses in 2018 . We can see that maximum trade is controlled by larger businesses employing more than 500 people with the manufacturing industry's differentiating factor. Large businesses export thrice in manufacturing industries compared to smaller businesses.

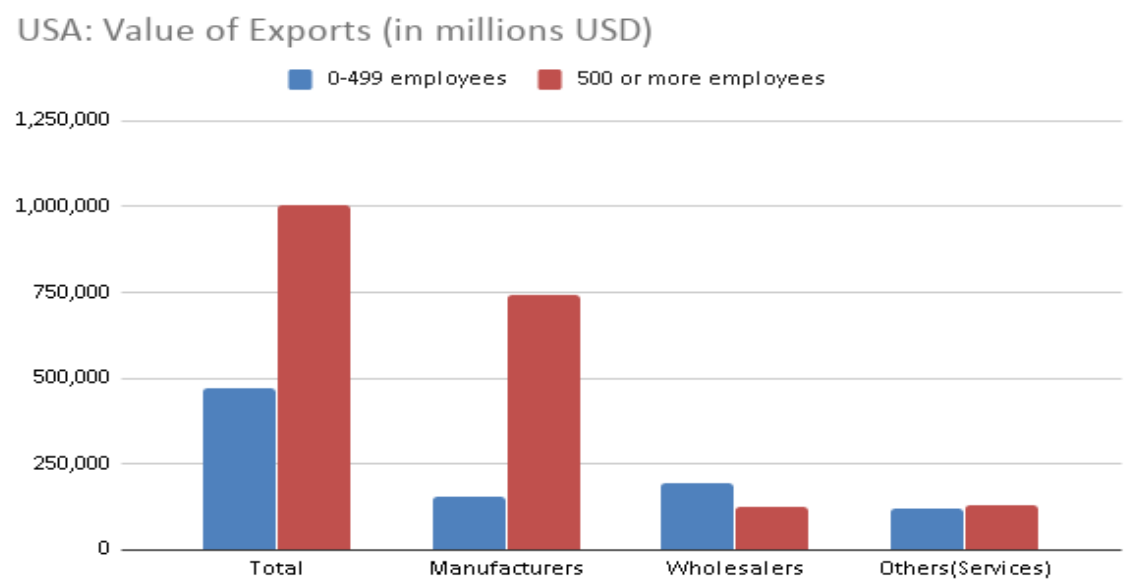

Figure 9. USA: Value of Exports (in millions USD) in 2018

Source: United States Census Bureau. 


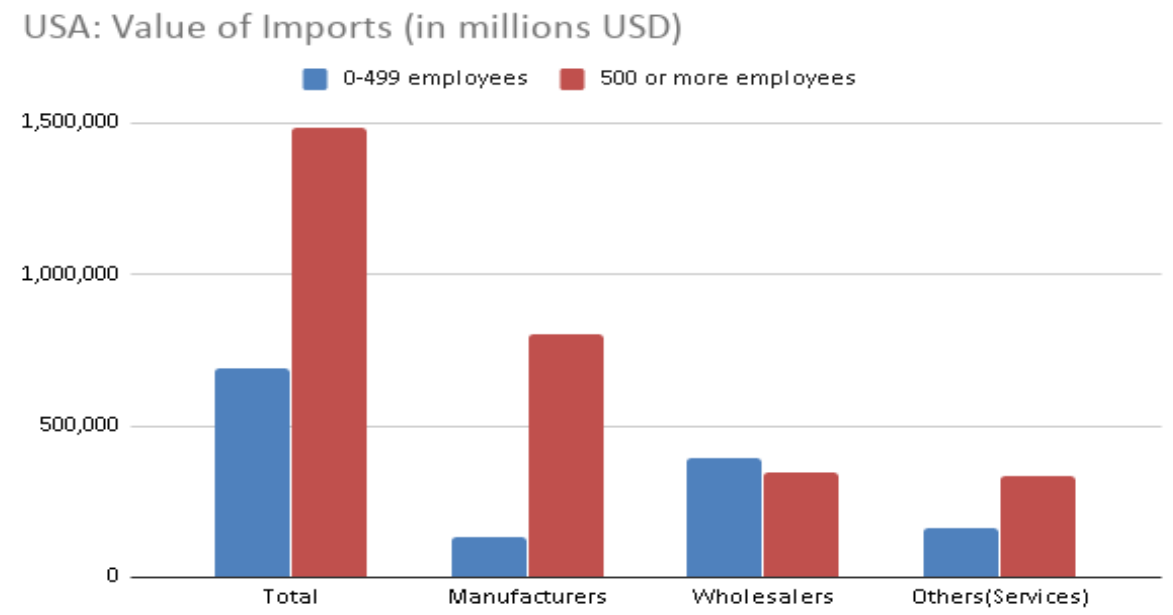

Figure 10. USA: Value of Imports (in millions USD) in 2018

Source: United States Census Bureau.

A similar trend is seen in overall trade with regards to imports (Figure 11). Manufacturing is dominated by the bigger companies, however, one interesting component to be observed is the domination of SMEs in wholesale trade in the U.S. As we previously noted, there are many wholesale and retail trade SMEs in the U.S. who are dominating this segment overall. Other sectors, mostly involving services, see more or less similar trade characteristics.

\section{Part III: The UK-U.S. Relationship}

This subsection addresses the paper's vital focus - the relationship between the UK and the U.S. concerning SMEs. A recent 2020 survey published by the Federation of Small Businesses highlights the U.S. as the most important destination for UK SME traders in terms of exports and imports. Figure 11 and 12 below show the importance of the trade relationship for SMEs in the coming three years. $46 \%$ of exporters indicated the U.S. as the top importance, with $31 \%$ of the importers noting the U.S. as a top import destination. With the latest dominance in wholesale and retail trade, turnover in both countries, and with growing concern for the protection of SMEs between the two countries, as cited in the previous section, we can expect a more reliable link in such sectors with better growth. However, the overall dominance in manufacturing goods in trade cannot be neglected.

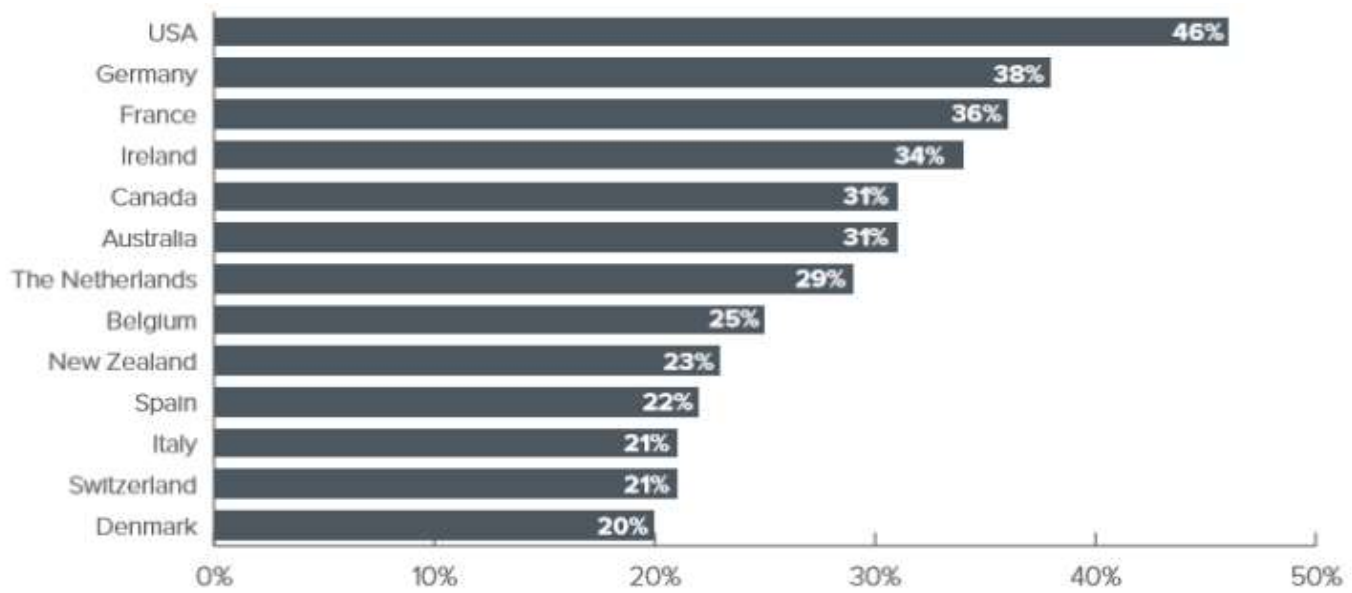

Figure 11. Most commonly reported 'important destination markets for UK SME exporters over the next three years

Source: FSB Trade research survey 2019. 


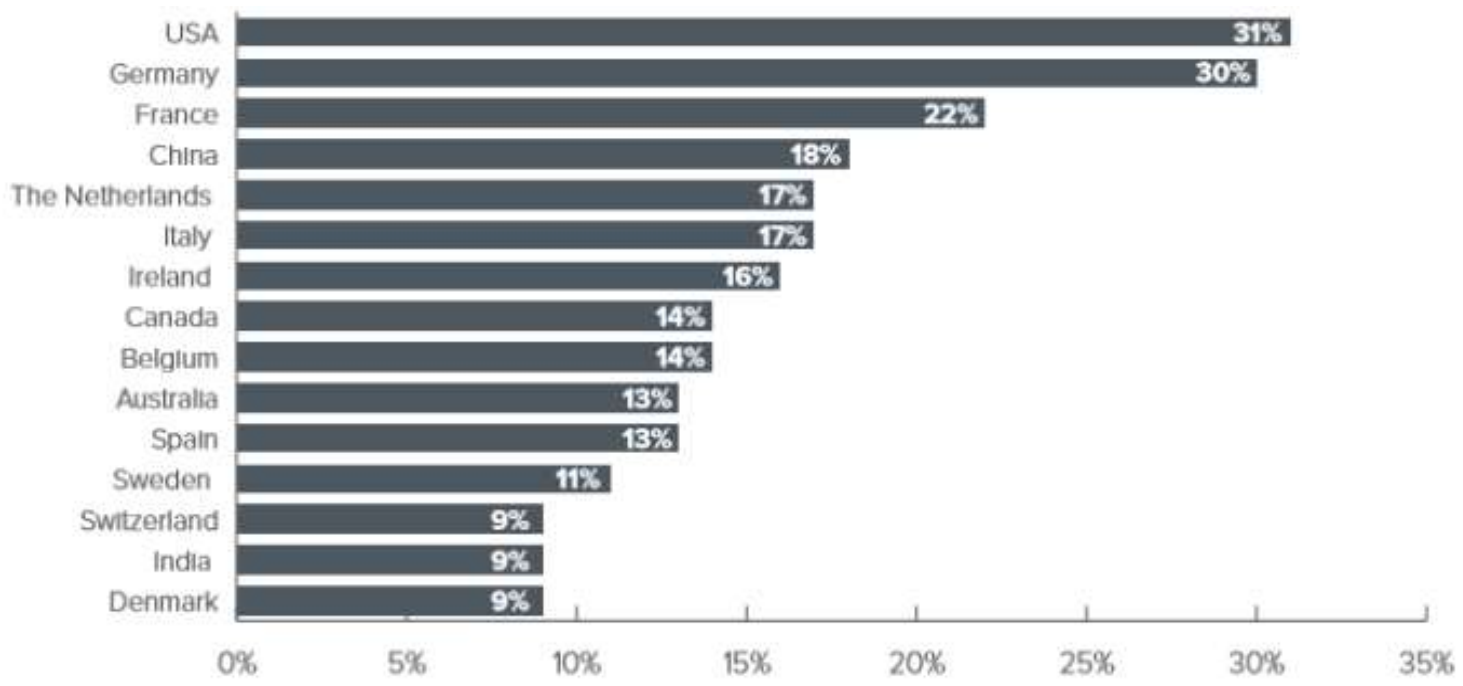

Figure 12. Most commonly reported 'important destination markets for SME importers over the next three years

Source: FSB Trade research survey 2019.

From the above data analysis and literature review, we see the strong and growing importance of SMEs in the UK and the U.S. in different sectors. However, with the COVID pandemic, SME businesses have been disrupted following little to no connection between the two continents. This poses several threats and challenges. A worldwide call for change in business patterns and the use of technology has forced SMEs to rework and rethink their strategies.

From a policy perspective, SMEs are extremely integral in the UK-U.S. partnership as they hold more than 95\% of businesses with employment close to $50 \%$ or more in both countries along with growing projections in SME trade.

The following sections aim to give a perspective on technology, trade policy, and the way forward under this SME study.

\section{Disruptive Technologies, SMEs and Trade Policy}

In this section, we lay out the different types of disruptive technologies that can rise in the post-COVID world, and their implications for SMEs in terms of opportunities created. Reflecting on the growth of the U.S. and U.K. economies, the establishment of jobs and wealth from disruptive innovation came with the large corporates who completely dominated the 19 th and most of the 20th-century economics.

Then came the 1980s, and this bit of economic wisdom went into full reverse with major corporations downsizing on both sides of the Atlantic and the proliferation of the SMEs. SMEs were on the cutting edge of innovation in the 1980s recovery after the deep recession in the late '70s to tackle the endemic inflation within both the U.K. and U.S. economies. That recovery was dominated by SMEs to such an extent that David Birch, at MIT, claimed companies with fewer than 100 employees were responsible for as many as eight out of ten new jobs in the 1980s [9], with many large corporations slow to respond to considerable shifts in disruptive technologies and new markets [10].

That evolved into the 1990s, where, after 30 years, it has translated into the growth of SMEs within sectorial supply chains to more giant corporations. For example, in the case of manufacturing, the assemblers, known as Original Equipment Manufacturers (OEMs), as SMEs are inherently dynamic, innovative, and entrepreneurial, in contrast to the sluggish corporate bureaucracies of the 1970s/80s. The very term SMEs evokes images of the service or retail sectors, where smaller companies are most common. If the issue is international competitiveness, 
however, one place to look is manufacturing, with "manufacturing" and "service" now inseparably interwoven and known as servitisation [11].

Manufacturing is a core capability allowing the new disruptive technologies to emerge from the SME supply chains within each manufacturing sector. The challenge now is to integrate that success across all market sectors in innovative, disruptive ways. The added challenges are learning how to develop technology and innovation that is best for specific markets, how to control the costs and, in particular, how to capitalise (finance) it. The UK is notoriously inadequate at financing its SME sector sufficiently [12], even though The City of London is one of the world's largest financial centres, along with Wall St., New York. The U.S., in contrast, excels at this capitalisation for emerging SMEs and start-ups of disruptive technologies. The challenge for SMEs is to be entrepreneurial while obtaining the capitalisation needed before earning enough profit to continue to invest and compete on a sustained basis within the SME supply chains they operate. That is more likely achieved within a cluster of SME supply chains collaborating and inter-linked together with their inherent entrepreneurship leadership and innovation within specific markets, new and old, for a rapid COVID economic recovery. That very entrepreneurship, innovation, and leadership courage to take on risk are found in abundance within the UK and U.S. SMEs [13].

According to the traditional view, large corporations bring efficiency, although with a certain rigidity, and SMEs bring flexibility with the instability of survivability. That can be mitigated somewhat within SME supply chains and clusters. SME supply chain developments have made a new kind of organisational structure possible. In this new SME supply chain model, it is not the size of a company that matters as much as the quality of the business relationships tying companies to each other throughout the supply chain. That dynamism within the sectorial SME supply chains is now dominative within the U.S. and UK economies. The fundamental unit of industrial production, for example, is no longer the individual company, but a decentralised network of SME supply chain companies.

SME networks consist of vertical links tying SME suppliers to large final assemblers such as the Airbus Group and the Boeing Company in the Aerospace Industry. In other cases, the links are horizontal, binding together several more or less equal SME companies competing to either supply the market directly or other companies with different geographical market share positions. The healthcare market is reflective of this. In both cases, these SME supply chain networks make continual innovation through a delicate balance of competition, cooperation, and market demand. The COVID pandemic has illustrated this within the aerospace supply chain as they have adapted to new markets. For example in healthcare, Marshall Aerospace and Defence Group along with its SME supply chain produced an alternative model of a ventilator [23] to increase the heart's efficiency by $25 \%$ compared to conventional ventilators, which among others equipped the UK National Health Service during the height of the COVID pandemic.

Sabel [14] spotted this trend in the early 1990s within manufacturing, describing "the corporation becomes more a federation of companies rather than a single organisational entity," tied together in a system that Sabel terms "collaborative manufacturing." We see it now as the established SME supply chain in each manufacturing market sector. As decentralised collaborative manufacturing spreads, dense regional clusters of highly specialised SMEs have been established. They flourished before the COVID economic shock. With many SMEs too small to do their R\&D and employee training etc., these they depend on outside institutions, universities, and community colleges, trade associations, and local, national, regional governments to provide or grant support these services collectively. Thus Sabel's 'metacorporation' is woven into the social fabric far more tightly than the vertically integrated corporation of the past.

An International Labor Organisation study [15] identifies two types of networks: "kingdoms" tie small suppliers to a large corporate customer in a vertical supplier chain, under the strategic direction of the corporation; "republics" join small, highly specialised companies to each other in a horizontal network where no one company dominates. These two models are not mutually exclusive. As befits the logic of flexibility, they are highly fluid. The same company can shift from one to another over a period of time or even belong to both simultaneously, particularly within Clusters. Porter [16] defines clusters as "geographic concentrations of interconnected companies and institutions in a particular field." Spanning a range of sectors that use core competencies or supply 
similar customer bases, the aero/space/defence market is a classic example. This established trend has created a new economic space for a particular SME that is close to the market, technologically, and dynamically linked to other companies in complex production networks. For the COVID recovery, we believe those SME cluster supply chains can then be projected into new market capture strategies rather than purely locational concentrations, to an OEM, as envisaged by Porter. That will create an emerging power base for SMEs and their supply chains, for market capture in their own right, while many of the corporations focus on-balance-sheet restructure and consolidation to survive from the COVID economic shock imposed on them.

In some clusters, government-funded agencies play significant roles by furnishing education and training or specialised transport attempting to resolve inherent structural market failures. The Northern (England) Powerhouse and levelling up the strategy of the present UK Government are classic examples. The North held back economically by poor transport interconnectivity between the North West to North East of England [17], following centuries of emphasis on transport networks radiating out from London benefiting the South East of England over the North and Midlands. In some, regional industry bodies provide vital organisational glue [18]. Therefore, the precise anatomy of each cluster is fundamentally different, and correspondingly so are its dynamic entrepreneurial forces. This can be overcome by bi-lateral coordination of key market SME clusters within the UK and the U.S. to project into global market capture strategies. This would have the added advantage of also being a rapid approach to play directly into market capture from the reset of the UK and U.S. diplomatic and trade relations with China, which has emerged from the COVID pandemic.

\section{The Importance of Rigorous Studies to Inform Trade Policy}

A country's capacity to build these flexible SME supply chain networks, or clusters, and project them into market capture constitutes a new kind of competitive advantage. With the emergence of a bilateral trade arrangement with the UK's departure from the EU, the world's fifth-largest economy could, with the U.S., achieve an enhanced competitive edge by targeting key industries and sectors together. Blending UK SMEs' innovation into the wellcapitalised U.S. SME base would be transformative either by enhancing existing supply chains in place or creating new ones. For example, as highlighted by the Covid-19 pandemic, there is an opportunity to do so in healthcare. Doing so would transform an existing market that is still dominated by political considerations rather than disruptive innovation. The resulting economic growth could be substantial as the global healthcare industry was worth $\$ 8.45$ trillion in 2018 and will be well over $\$ 10$ trillion by 2022 [19]. The U.S. spends twice per capita $(\$ 10,200)$ of other countries, therefore ripe for the disruptive innovation UK SMEs could bring to the fore. Correspondingly, there are over 750,000 companies in the U.S. healthcare sector that would likely create a similar growth of UK SMEs in the sector. For example, the disruptive innovation on the Internet would lower operational and clinical inefficiencies while creating a $\$ 200$ billion per year market [20]. The merger and cooperation of the UK and U.S. SME supply chains in the healthcare sector would accelerate those efficiencies resulting in the full emergence of integrated healthcare systems to be projected into subsequent market capture strategies.

Such dynamic SME supply chain clusters can be resources for operational capability, and well-being of continuous innovation as their skilled workforces under entrepreneurial leadership concentrate on finding solutions to market opportunities [18]. By promoting UK-U.S. bi-lateral cluster development, SME entrepreneurial leaders can build on a cluster's natural economic advantage to create more effective market capture strategies within the supply chains they operate. Particularly within a bi-lateral UK-U.S. SME clusters approach.

A combination of an intimate collaboration between UK and U.S. clusters, and the intense competition resulting, will drive cluster dynamics in new directions and rapidly into new markets. Economists call the positive externalities of clustering to be readily identified and built on bi-laterally between UK and U.S. SMEs. Vital to a V-shaped COVID economic recovery that will be dependent on the vibrant growth of SMEs.

Research into the last recovery from an economic shock [21] shows that any regional economic growth is highly correlated with the presence of many SME entrepreneurial employers, not a few big ones. It is found that industries with SMEs and more start-ups enjoyed faster employment growth than other industries. That effect, we believe, can be multiplied by careful integration of the SMEs sectors between the U.S. and UK. That is where economic and job growth will materialise. Although civil servants and politicians tend to enjoy announcing a large corporations' arrival through Foreign Direct Investment (FDI) because people tend to think that will mean lots of 
job openings, that is not the case in a rapidly evolving economy and markets sectors driven by innovation. They are also all too likely to guess wrong about which industries are worth attracting.

Furthermore, large corporations often generate little employment growth, even if they are doing well. The SME sector is the key. The combination of the U.S. and UK vibrant SME sectors by more effectively coordinating and cooperating under their entrepreneur leadership rather than Government directed, is the way to go. It is an unique opportunity, from the COVID economic shock, to do so in a range of sectors with existing vibrant SME supply chains within a full range of sectors, both countries excel notably aero/space, defence, healthcare, digital, transportation, tourism, etc. In order to capture all these nuances, we ought to develop and work on rigorous dataintensive global supply chain economic models that can capture the complex realities of linkages across sectors and countries. This also along with behavioural aspects of the SMEs, consumers and governments, in different scenarios of futuristic possibilities.

\section{Conclusions and the Way Forward}

The rediscovery of small business in the 1980s quite rightly emphasised the creative energies of individual entrepreneurs and the benefits of relatively unconstrained competition. The COVID economic recovery is the chance to achieve that again with the fundamental dynamics of the U.S.-UK economies and the sectoral SME supply chains. It has the same happenstance as the re-emergence from the dramatic recession of the 1970s to the booming 1980s within the UK and U.S. economies that was itself dominated by SMEs' growth.

This competitive strategy's precondition is a radical increase in SME supply chain flexibility and its core competencies across a full range of market sectors. This space for greater flexibility can achieved by bilateral free trade agreements between the countries which aid better trust, reciprocity and trade interconnectedness in both markets. The sustained growth of SMEs will be the key determinant in the COVID economic recovery for the UK and U.S. economies. Government stimulus [22] combined with UK and U.S. private equity firms continuing to target and finance integration of the key SME supply chains will ensure a competitive edge in global market capture for the UK-U.S. Partnership.

Funding: self-funded.

Author contribution: conceptualization, Raymond Davies, Badri Narayanan Gopalakrishnan; data curation, Adhithya Balasubramanian; formal analysis, Adhithya Balasubramanian; funding acquisition, Adhithya Balasubramanian, Raymond Davies and Badri Narayanan Gopalakrishnan; investigation, Adhithya Balasubramanian, Raymond Davies and Badri Narayanan Gopalakrishnan; methodology, Adhithya Balasubramanian, Raymond Davies and Badri Narayanan Gopalakrishnan; project administration, Badri Narayanan Gopalakrishnan; resources, Adhithya Balasubramanian, Raymond Davies and Badri Narayanan Gopalakrishnan; software, Adhithya Balasubramanian, Raymond Davies and Badri Narayanan Gopalakrishnan; supervision, Adhithya Balasubramanian, Raymond Davies and Badri Narayanan Gopalakrishnan; validation, Adhithya Balasubramanian, Raymond Davies and Badri Narayanan Gopalakrishnan; visualization, Adhithya Balasubramanian; writing - original draft, Adhithya Balasubramanian, Raymond Davies and Badri Narayanan Gopalakrishnan; writing - review \& editing, Adhithya Balasubramanian.

\section{References}

1. Bateman, M. (2017). Bringing the local state back into development: the 'local developmental state' and the promotion of sustainable economic development and growth from the bottom-up. DOI: $\underline{10.2139 / \mathrm{ssrn} .3057226 .}$.

2. Carroll, J., Mooney, P., \& O'Toole, C. (2016). Irish SME Investment in Economic Recovery. Quarterly Bulletin 02/April 16, 73. Available at: https://ideas.repec.org/a/cbi/qtbart/y2016m03p77-91.html.

3. Maluck, J., Glanemann, N., \& Donner, R. V. (2018). Bilateral trade agreements and the interconnectedness of global trade. Frontiers in Physics, 6, 134. DOI: https://doi.org/10.3389/fphy.2018.00134.

4. Ulker, Demet \& Yilmazkuday, Hakan. (2012). Bilateral versus Multilateral Free Trade Agreements: A Welfare Analysis. Review of International Economics. DOI: https://doi.org/10.1111/roie.12131. 
5. Melluso, N., Fareri, S., Fantoni, G., Bonaccorsi, A., Chiarello, F., Coli, E., ... \& Manafi, S. (2020). Lights and shadows of COVID-19, Technology and Industry 4.0. Available at: https://arxiv.org/ftp/arxiv/papers/2004/2004.13457.pdf.

6. Morita-Jaeger, Minako and Borchert, Ingo. (2020). The Representation Of SME Interests In Free Trade Agreements: Recommendations For Best Practice. Federation of Small Businesses (FSB). Available at: https://blogs.sussex.ac.uk/uktpo/files/2020/01/FSB-Trade-TPO-Report.pdf.

7. Preparations for Post-Brexit Trade Deals Continue with US, Australia. (2018, March 29). International Centre for Trade and Sustainable Development. Available at: http://www.ictsd.org/bridgesnews/bridges/news/preparations-for-post-brexit-trade-deals-continue-with-us-australia.

8. European Union. (2014). Small and Medium Sized Enterprises and the Transatlantic Trade and Investment Partnership. Available at: https://trade.ec.europa.eu/doclib/docs/2015/april/tradoc_153348.pdf.

9. David L. Birch (1984). The Role of High Technology Firms in Job Creation, Working Paper of the MIT Program on Neighborhood and Regional Change. Cambridge: Massachusetts Institute of Technology. Available at: https://core.ac.uk/download/pdf/6793235.pdf.

10. Ralph Landau, Nathan Rosenberg (1986). The Positive sum strategy: harnessing technology for economic growth. National Academy of Engineering, page 517. Available at: https://www.nap.edu/catalog/612/thepositive-sum-strategy-harnessing-technology-for-economic-growth.

11. Ashish Saxen (2020). Servatization: The Next Wave of Growth for Manufacturing. Wipro Ltd., India. Available at: https://www.wipro.com/process-and-industrial-manufacturing/servitization-the-next-wave-ofgrowth-for-manufacturing/.

12. James Hurley (2014). British Business Bank seeks to boost SME lending. The [London] Times. Available at: https://www.ft.com/content/a5942bae-2d1c-49db-af55-ad36654d23f1.

13. Jeff Stibel (2009). How Small Businesses Win Big in Tough Economies - HBR. Available at: https://hbr.org/2009/08/how-small-businesses-win-big.

14. Charles Sabel (1995). The New Division of Labour, Emerging forms of Work Organisation in International Perspective. Edited by Wolfgang Littek and Tony Charles, pp. 57-94. DOI: https://doi.org/10.1515/9783110890747.

15. Howard, R. (1990). Can Small Business help Countries Compete. Available at: https://apps.dtic.mil/dtic/tr/fulltext/u2/a257032.pdf.

16. Porter, Michael E. (1990). The Competitive Advantage of Nations. New York: The Free Press. Available at: http://www.afi.es/eo/The\%20competitive\%20advantage\%20of\%20nations\%20\%28Porter\%20HBR\%20mar zo-abril\%201990\%29.pdf.

17. Dan Jarvis (2020). Time to accelerate the new deal for the north. The [London] Times. Available at: https://www.thetimes.co.uk/article/time-to-accelerate-the-new-deal-for-the-north-xjwgpq7lh.

18. Andrew Mair (2020). Mobilising the Midlands Aerospace Cluster. Midlands Aerospace Alliance Report. Available

at:

https://www.midlandsaerospace.org.uk/documents/Mobilising\%20the\%20Midlands\%20Aeropace\%20Clust er\%20--\%20White\%20Paper.pdf.

19. Global Healthcare Market: Key Opportunities \& Strategies (2019). Available at: https://www.businesswire.com/news/home/20190625005862/en/The-11.9-Trillion-Global-HealthcareMarket-Key-Opportunities-Strategies-2014-2022---ResearchAndMarkets.com.

20. Kolorama (September 19th, 2019). Internet of Things (IoT) in Healthcare' Report. Available at: https://www.grandviewresearch.com/industry-analysis/internet-of-things-iot-healthcare-market.

21. Edward L. Glaeser and William R. Kerr (July-August 2010). The Secret to Job Growth: Think Small. Available at: https://hbr.org/2010/07/the-secret-to-job-growth-think-small.

22. UKEF Press Release (7th December 2020). Radical shake up to government export finance support for small businesses. Available at: https://www.gov.uk/government/news/radical-shake-up-to-government-exportfinance-support-for-small-businesses.

23. Hexagon and MSC Software Case study, 'Marshall Aerospace \& Defence Group', Hexagon Manufacturing Intelligence. Available at: https://www.hexagonmi.com/solutions/case-studies. 